\title{
Response of suspended sediment concentration to water and sediment regulation in yellow river estuary
}

\author{
Hongling ZHAO ${ }^{1}$, Haibo YANG ${ }^{1,2, \text { a }}$, Yunfei LI ${ }^{1}$, Ruifei $\mathrm{Li}^{1}$ \\ ${ }^{1}$ School of water conservancy and environment engineering, Zhengzhou University, Zhengzhou \\ 450001, China \\ ${ }^{2}$ State key Laboratory of Hydroscience and Engineering, Tsinghua University Beijing 100084 , \\ China \\ azzutyhb@163.com
}

Keywords: Water and Sediment regulation, Remote Sensing, Suspended sediment concentration, Yellow River Estuary

Abstract. By using GIS and RS technologies, coastal suspended sediment concentration (SSC) of Yellow River Estuary were retrieved and analyzed in two periods, normal period (NP) that means before 2002 and water \& sediment regulation period (WSRP) that means after 2002, to reflect the temporal and spatial change for disclosing the water $\&$ sediment regulation effect in recent years. The results show that, (1) due to water and sediment decrease, the annual means of sediment ratio (T/s) decreased from 8.228 in NP to 1.585 in WSRP, but the difference of annual means of sediment amount in Lijin station and in Huayuankou station increase from -0.2568 billion tons in NP to 0.0494 billion tons in WSRP which can reflect that river channel deposition turned to river channel erosion in Yellow River downstream because of water \& sediment regulation; (2)annual mean SSC of NP increases from 238mg/L ( pre_flood season) to 293mg/L (after_flood season) from 1986 to 2001, but annual mean SSC of WSRP increased with a higher rate, from $192 \mathrm{mg} / \mathrm{L}$ (before_WSR) to $264 \mathrm{mg} / \mathrm{L}$ (after_WSR) from 2002 to 2012. Due to water \& sediment regulation, river erosion in downstream is obvious, and the sediment discharge in Yellow River mouth is improved, and then high concentration of sediment spreads far away in sea than before.

\section{Introduction}

After 1986 due to the flow decrease and cut-off in 90's in the downstream of Yellow River, sediment accumulation, main channel shrinking and the reduction of flood carrying capacity, had been affecting the safety and environment ${ }^{[1]}$. The Yellow River Conservancy Commission started the project of water and sediment regulation (WSR) from 2001 which aimed to regulate and control the flow and sediment transport relationship of the lower reaches through reservoirs on the main streams and tributaries to create balance between water and sediment ${ }^{[2-3]}$. During the WSR, a part of flow, about $20 \%$ of the whole year, can transport $40 \%$ sediment of the whole year into estuary ${ }^{[4]}$. But the process of water-sediment transportation is different to WSR. So study on the distribution and concentration of suspended sediment in estuary is useful and important to reveal the effect of the water and sediment regulation.

\section{Data and method}

Data. After collecting the remotely sensed images of Yellow River Estuary (YRE) in 23 years in normal periods (NP) in 1986-2001 and water \& sediment regulation periods (WSRP) in 2002-2013, sediment concentration in 46 periods are analyzed to study the difference of sediment transportation and distribution. Selected images are as shown in table1. 
Table 1 selected images

\begin{tabular}{|c|c|c|c|c|c|c|c|}
\hline \multirow{2}{*}{\multicolumn{3}{|c|}{$\begin{array}{c}\text { Normal period(1986-2001) } \\
\text { Image date } \\
\end{array}$}} & \multicolumn{5}{|c|}{ water and sediment regulation periods } \\
\hline & & & \multirow[b]{2}{*}{ year } & \multicolumn{2}{|c|}{ WSR date } & \multicolumn{2}{|c|}{ Image date } \\
\hline year & $\begin{array}{l}\text { Pre- } \\
\text { flood }\end{array}$ & $\begin{array}{l}\text { After- } \\
\text { flood }\end{array}$ & & start & end & before & after \\
\hline 1986 & $4 / 18$ & $8 / 8$ & 2002 & $7 / 4$ & $7 / 15$ & $2 / 1$ & $9 / 29$ \\
\hline 1987 & $6 / 24$ & $8 / 18$ & 2003 & $9 / 6$ & $9 / 18$ & $8 / 31$ & $10 / 18$ \\
\hline 1989 & $4 / 10$ & $10 / 3$ & 2004 & $6 / 19$ & $7 / 13$ & $5 / 13$ & $9 / 18$ \\
\hline 1991 & $4 / 16$ & 9/23 & 2005 & $6 / 15$ & $7 / 3$ & $4 / 30$ & $7 / 19$ \\
\hline 1992 & $5 / 20$ & $8 / 24$ & 2006 & $6 / 15$ & $7 / 3$ & $6 / 4$ & $10 / 2$ \\
\hline 1995 & $5 / 29$ & 9/18 & 2007 & $6 / 19$ & $7 / 7$ & $6 / 15$ & $9 / 11$ \\
\hline 1996 & $5 / 15$ & $8 / 19$ & 2008 & $6 / 19$ & $7 / 14$ & $3 / 5$ & $9 / 13$ \\
\hline 1998 & $5 / 5$ & $8 / 25$ & 2009 & $6 / 19$ & $7 / 8$ & $6 / 12$ & $8 / 31$ \\
\hline 1999 & $5 / 24$ & $10 / 7$ & 2010 & $6 / 19$ & $7 / 7$ & $6 / 15$ & $9 / 11$ \\
\hline 2000 & $6 / 11$ & 9/15 & 2011 & $6 / 19$ & $7 / 11$ & $6 / 2$ & $9 / 22$ \\
\hline 2001 & $6 / 6$ & $9 / 2$ & 2012 & $6 / 19$ & $7 / 9$ & $6 / 4$ & $8 / 23$ \\
\hline- & - & - & 2013 & $6 / 19$ & $7 / 10$ & $5 / 6$ & $8 / 10$ \\
\hline
\end{tabular}

Suspended sediment concentration retrieval by using RS. There are many models about water body and spectral character research. Using spectral measurement and experiment at sea, the relationship between measured concentration and remote sensing spectral reflectance of different band combinations are built by using lineal regression ${ }^{[5]}$. Because of the combination of R3/RS with a higher relation, in this paper, the equation is suggested to us the following equation in (Table 2).

$$
\mathrm{S}=1.6821 \cdot \exp (5.1038 \cdot \mathrm{R} 3 / \mathrm{R} 2)
$$

Table 2 The relationship between suspended sediment concentration and spectral reflectance of different band combination

\begin{tabular}{ccc}
\hline $\begin{array}{c}\text { Band } \\
\text { combination }\end{array}$ & equation & correlation coefficient \\
\hline $\mathrm{R} 3 / \mathrm{R} 1$ & $\mathrm{R} 3 / \mathrm{R} 1=0.3201 \mathrm{Ln}(\mathrm{S})+0.293$ & 0.9614 \\
$\mathrm{R} 3 / \mathrm{R} 2$ & $\mathrm{R} 3 / \mathrm{R} 2=0.1683 \mathrm{Ln}(\mathrm{S})+0.2454$ & 0.9676 \\
$\mathrm{R} 4 / \mathrm{R} 1$ & $\mathrm{R} 4 / \mathrm{R} 1=-9 \mathrm{E}-07 \mathrm{~S} 2+0.0027 \mathrm{~S}+0.0977$ & 0.9558 \\
$\mathrm{R} 4 / \mathrm{R} 2$ & $\mathrm{R} 4 / \mathrm{R} 2=-5 \mathrm{E}-07 \mathrm{~S} 2+0.0015 \mathrm{~S}+0.062$ & 0.9549 \\
$(\mathrm{R} 4+\mathrm{R} 3) / \mathrm{R} 2$ & $(\mathrm{R} 4+\mathrm{R} 3) / \mathrm{R} 2=0.368 \mathrm{Ln}(\mathrm{S})-0.178$ & 0.9445 \\
\hline
\end{tabular}

Data processing. There are two steps to process the RS data:

(1) Data pre-processing. By using destripe tool, the landsate images are modified, and then radiation rectification, multi-band fusion and image subset are processed to obtain the entire study region.

(2) Suspended sediment concentration calculation. Different periods of sediment concentration and distribution can be calculated according to the equation mentioned above.

\section{Result}

Water-sediment condition comparison in normal period and water-sediment regulation period. In this paper, related data of the hydrometric stations in the yellow river including Lijin and Huayuankou were analyzed and the results show that water and sediment amount decreased dramatically. From 1986 to 2001, the annual average runoff and sediment discharge is 13.735 billion $\mathrm{m}^{3}$ and 0.352 billion tons, which is only $32.9 \%$ and $43.8 \%$ comparing to the value from 1950 to 1985 .

The sediment transport between Huayuankou station and Lijin station can disclose the sediment accumulation or erosion condition. Although the water and sediment in WSR period decreased in comparison with in normal period, the sediment runoff difference between Lijin and Huyuankou have 
been turning from negative to positive, which revealed that more sediment were transported to sea in the channel from 2002 (Fig.1).

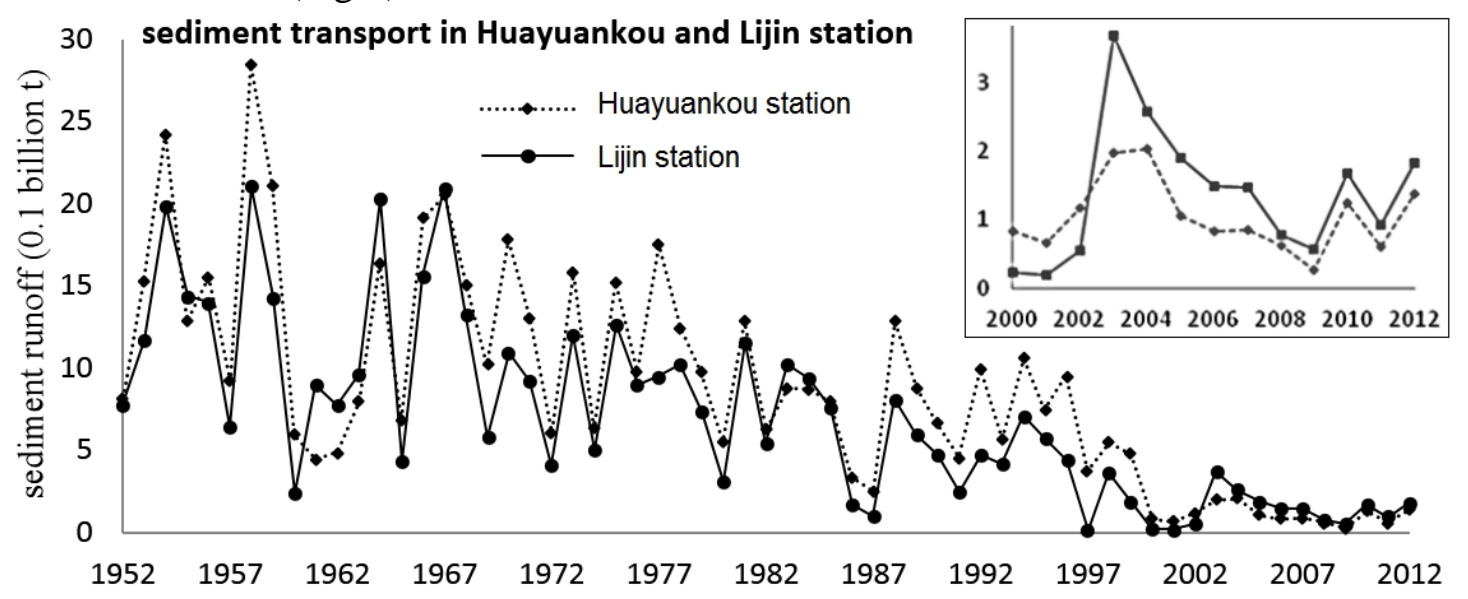

Fig.1 Sediment runoff change of Huayuankou station and Lijin station

Sediment concentration change analysis. As the area directly affected by the water and sediment discharged into the sea, the estuary region of Yellow River can best reflect the effects of water \& sediment regulation, the sediment in this area is under the combined force of the river dynamic and the ocean dynamic. The suspended sediment concentration distributions of several years are shown in Fig. 2. As shown in the figure, the sediment in the estuary area was distributed mostly along the coast and the concentration of which decreased quickly as the offshore distance increases, the suspended sediment concentration (SSC) in flood season was noticeably higher than that of pre-flood season. All of the peak points of SCS were nearby the estuary, which indicates that a large amount of sediment was deposited in estuary area. This provided the main source of power for the land-creation process of the Yellow River. The SSC distribution shows that the ocean dynamic posed on suspended sediment mainly parallels the coast and has a north-south orientation, this coincides with the character of the ocean dynamic in the estuary area. Only a small amount of suspended sediment dispersed northwards, while most of it dispersed southwards to Laizhou Bay under the combined force of the river dynamic and the ocean dynamic. The high SSC zone in the estuary area was normally connected with the high SSC zone in Laizhou Bay area.

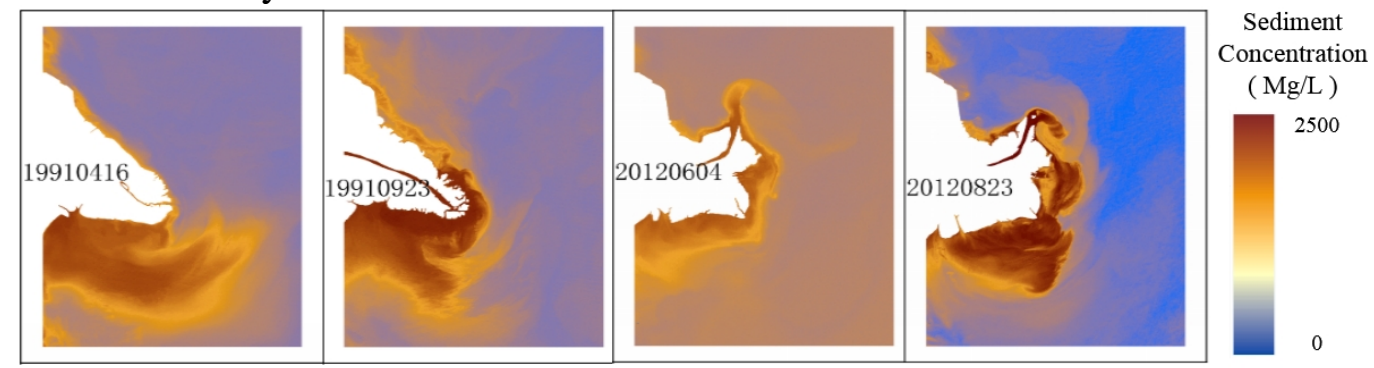

Fig.2 The inversion image of sediment concentration of Yellow River Estuary

Division analysis of sediment concentration. To quantitatively analyze the distribution character of SSC in the estuary area in greater detail and compare the difference between SSC in areas of different directions and different distances offshore in the normal periods(NP) in 1986-2001 and that in water \& sediment regulation periods(WSRP) in 2002-2013, the sea area in the Yellow River Estuary(YRE) was equally divided into 4 directions according to 45 degrees, and then three buffer zone were set $(5 \mathrm{Km}, 10 \mathrm{Km}, 20 \mathrm{KM})$ based on the coastlines extracted from each image, thus dividing the YRE area into 12 zones.

The annual means of SSC of each zone in NP and WSRP was calculated and shown in Fig.3. It can be seen clearly that SSC of each zone in flood season was higher than that of pre-flood season. The average SSC of all the 12 zone in NP in flood season and pre-flood season were 238mg/L and 293mg/L respectively, while the figure in WSRP were $192 \mathrm{mg} / \mathrm{L}$ and $264 \mathrm{mg} / \mathrm{L}$ respectively. Due to the fact that the river dynamic decreases rapidly as the offshore distance increases, change ranges of the annual 
average of SSC in each zone decreased quickly as offshore distance increases in both NP and WSRP, this change ranges of zones within $5 \mathrm{Km}$ distance offshore were largest, while in zones within $20-30 \mathrm{Km}$ distance offshore the change ranges were very slight, this indicates that the suspended sediment diffusion monstly depends on the ocean dynamic in zones that are more than $20 \mathrm{Km}$ offshore, and the river dynamic in these zones were very slight. This also indicates that SSC in each zones have a consistent response to the factors that cause the change of SSC. It also can be seen that the change ranges between flood season and pre-flood season in each year in WSRP were higher than that in NP.
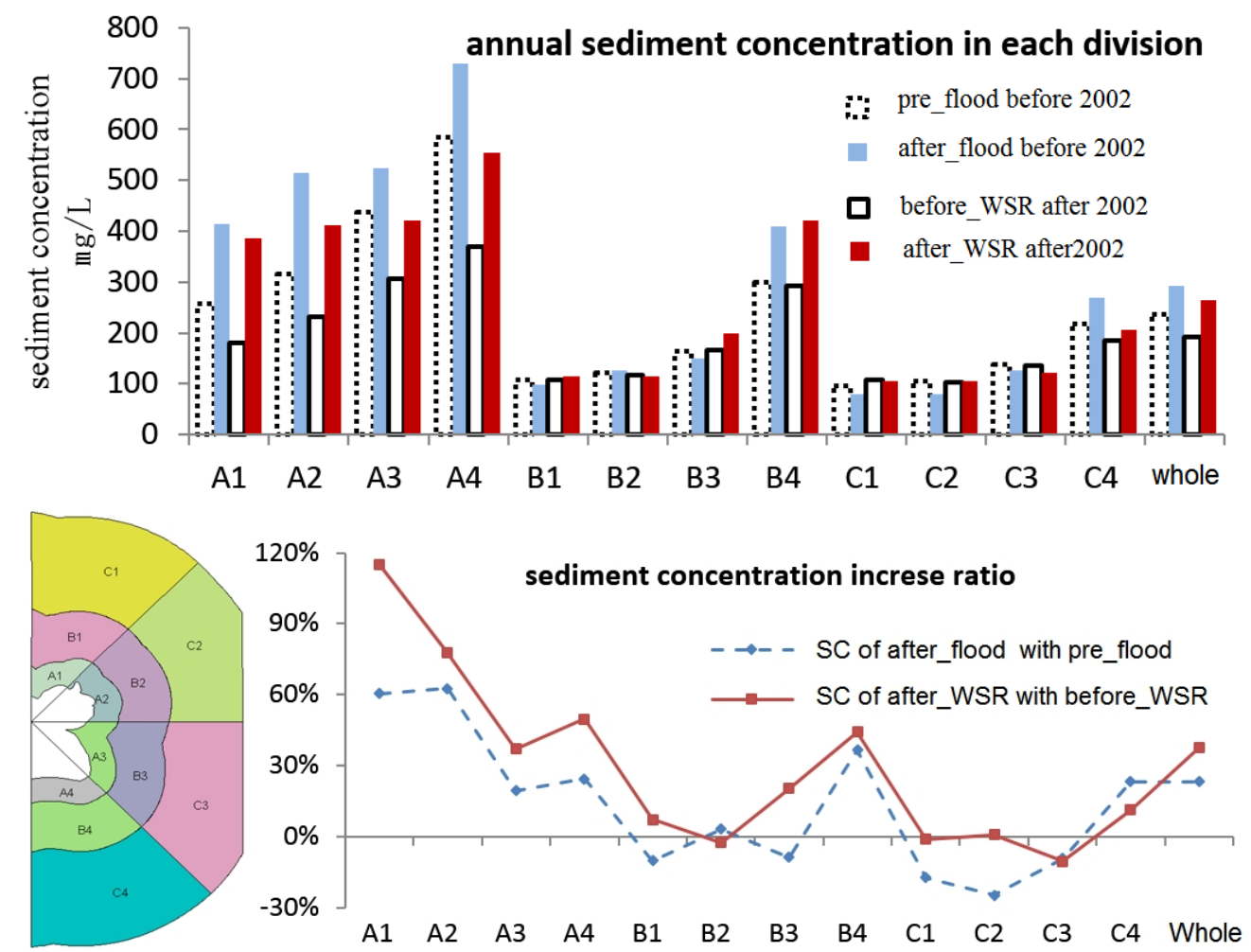

Fig.3 Annual means of sediment concentration in different zones

\section{Conclusions}

The water \& sediment regulation has changed the flow and sediment condition of Yellow River, based on the collected remote sensing images of the Yellow River Estuary (YRE) in 23 years in normal periods(NP) in 1986-2001 and water \& sediment regulation periods(WSRP) in 2002-2013, coastal lines and suspended sediment concentration (SSC) are retrieved and analyzed together with the water and sand data to reflect the temporal and spatial change for disclosing the water \& sediment regulation effect in recent years. The results show that:

(1) The statistics of the water and sand data shows that due to water \& sediment regulation, the annual incoming sediment coefficient droped from $0.06 \mathrm{~kg} . \mathrm{s} / \mathrm{m} 6$ in NP to $0.02 \mathrm{~g} . \mathrm{s} / \mathrm{m} 6$ in WSRP, annual means of sediment ratio (T/s) decreased from 8.228 in NP to 1.585 in WSRP, proportional relationship between water and sediment has improved. The difference of annual means of sediment amount in Lijin station and in Huayuankou station increase from -0.2568 billion tons in NP to 0.0494 billion tons in WSRP, which reflects that river channel deposition has turned to river channel erosion in Yellow River downstream because of water \& sediment regulation, meanwhile the gap between the proportion of water and sediment in flood season and that of dry season narrowed. The sondition of river channel deposition improved noticeably.

(2) Most of it dispersed southwards along the coast to Laizhou Bay under the combined force of the river dynamic and the ocean dynamic. The annual average SSC of YRE in NP increased from $238 \mathrm{mg} / \mathrm{L}$ in pre-flood season to $293 \mathrm{mg} / \mathrm{L}$ in flood season, while the figure in WSRP were $192 \mathrm{mg} / \mathrm{L}$ and $264 \mathrm{mg} / \mathrm{L}$ respectively. the rise of the SSC from pre-flood season to flood season in each year in WSRP were 
higher than that in NP, this can also reflect that river channel erosion in Yellow River was noticeable, and the sediment discharge in Yellow River mouth increased. Tater \& sediment regulation has led to an enhancement in the river dynamic, high concentration of sediment spreads far away in sea than before.

\section{Acknowledgements}

This work was financially supported by Open Research Fund Program of State key Laboratory of Hydroscience and Engineering (sklhse-2012-B-03) and Science and technology project of Henan Province (142102210069).

\section{References}

[1] Bi Naishuang. Suspended sediment diffusion and seasonal variation and scouring effect of the adjacent waters to Yellow River Delta[D].Ocean University of China,2009.(in chinese)

[2] Li Guoying, Sheng Lianxi. Science China. Tech Sci. 2011,54: 924-930

[3] Wang Puqing. The distribution characteristics of sedimentation in Xiaolangdi reservoir on it's early use[J]. Yellow River, 2012,10:26-27. (in chinese)

[4] XU Guobin, SI Chundi. Effect of Water and Sediment Regulation on Lower Yellow River[J]. Trans. Tianjin Univ. 2009, 15: 113-120

[5] Fan Hui, Huang Haijun, Tang Junwu. Spectral Signature of Waters in Huanghe Estuary and Estimation of Suspended Sediment Concentration from Remote Sensing Data[J].Geomatics and Information Science of Wuhan University,2007,07:601-64. (in chinese) 